\title{
Análise comparativa dos indicadores sociais internos: estudo de caso nas usinas Itamarati S/A e Barralcool S/A
}

\author{
Ricardo de Azevedo Vilella
}

Universidade do Estado de Mato Grosso - UNEMAT, Campus Tangará da Serra

Brasil

Graduado em Ciências Contábeis pela Universidade do Estado de Mato Grosso (UNEMAT), Campus Tangará da Serra

\section{Luciênio Rosa e Silva Junior}

Universidade do Vale do Rio dos Sinos - UNISINOS

Universidade do Estado de Mato Grosso - UNEMAT, Campus Tangará da Serra

Brasil

Doutorando em Administração pela Universidade do Vale do Rio dos Sinos (UNISINOS)

Professor do Curso de Ciências Contábeis da Universidade do Estado de Mato

Grosso (UNEMAT), Campus Tangará da Serra

\section{Vanderleia Aparecida da Silva}

Universidade do Estado de Mato Grosso - UNEMAT, Campus Tangará da Serra Brasil

Professora do Curso de Ciências Contábeis da Universidade do Estado de Mato Grosso (UNEMAT), Campus Tangará da Serra

\section{Josiane Silva Costa}

Universidade do Estado de Mato Grosso - UNEMAT, Campus Tangará da Serra Brasil

Professora do Curso de Ciências Contábeis da Universidade do Estado de Mato Grosso (UNEMAT), Campus Tangará da Serra

Artigo submetido em: 06/11/2016

Aprovado em: 05/02/2018

\section{RESUMO}

O objetivo desta pesquisa foi identificar os percentuais investidos no bem estar dos funcionários em empresas do setor sucroenergético, Usinas Itamarati S/A e Usina Barralcool S/A, nos períodos de 2010 a 2012, possibilitando uma comparação entre os dados por meio de tabelas e quadros, identificando qual das empresas mais investiu nos indicadores sociais internos. A pesquisa possui natureza bibliográfica e documental, e para alcançar os objetivos propostos utilizou métodos quantitativos e descritivos. Verificou dados contidos nos Balanços Sociais das empresas em estudo e identificou os valores médios investidos por funcionário nos indicadores internos alimentação, saúde, segurança e medicina do trabalho, capacitação e 
desenvolvimento profissional, creche ou auxílio creche, previdência privada, educação e cultura, participação nos lucros e resultados e em outros benefícios. Foi observado que a Usinas Itamarati S/A se destacou nos investimentos em outros benefícios, alimentação e saúde, enquanto a Usina Barralcool S/A priorizou os investimentos em alimentação, outros benefícios e participação dos lucros e resultados.

Palavras Chaves: Balanço Social. Responsabilidade Social. Receita Líquida.

\section{INTRODUÇÃO}

Para que ocorra a diminuição da desigualdade social, as entidades empresariais têm repensado sobre seu desenvolvimento social, mesmo que não existam leis específicas que exijam delas maior responsabilidade nessa questão, mas por motivo de sobrevivência no mercado, uma vez que faz parte da realidade o constante aumento da conscientização do público na questão do bem estar da sociedade (FREY; MARCUZZO; OLIVEIRA, 2008).

Além de desenvolver suas atividades operacionais, as empresas devem desempenhar seu papel social, contribuindo diretamente com o bem estar de seus funcionários e da comunidade em geral (SILVA; FREIRE, 2001). Segundo Tinoco (2006) a grande responsabilidade social das entidades é, além de gerar renda e emprego, atender as demandas e interesses dos diversos participantes envolvidos, e especialmente divulgar com transparência à todos os agentes sociais sua inserção no contexto econômico, financeiro, social e ambiental.

Devido às exigências do público, as empresas necessitam demonstrar seus investimentos e sua responsabilidade diante dos fatores sociais em determinado período, através de instrumento que evidencie de forma simples e fidedigna estas informações. Para uma apresentação que reúna todas as informações sobre projetos, benefícios e ações sociais voltados para investidores, funcionários, comunidade e analistas de mercado, as empresas contam com um instrumento contábil de gestão e informações denominado Balanço Social (TORRES JUNIOR; SILVA, 2008).

O Balanço Social é uma importante ferramenta de demonstração, que espelha a situação social da empresa, revelando o clima que a rege, criando, mesmo de uma forma implícita, avanços nas relações entre a direção e empregados. Apresenta certa realidade econômica e social das empresas, podendo ser interpretado e avaliado (TINOCO, 2006). Possui como principal finalidade a divulgação ao público, seja interno ou externo, sobre suas ações adotadas no âmbito social, bem como valores investidos em indicadores sociais externos e internos (SOUZA, 2011).

É de necessidade da sociedade saber sobre a responsabilidade e os esforços das empresas na melhoria social, e a sua divulgação reflete de forma positiva para a organização 
do ponto de vista da sociedade (TINOCO; KRAEMER, 2006). Sobre a Responsabilidade Social, Neto e Froes (1999) relatam que, se assumida de forma consistente e inteligente, pode contribuir decisivamente para a sustentabilidade e o desempenho da empresa.

Com o interesse do público sobre o desempenho social das empresas, tornou-se considerável analisar as evoluções dos investimentos em Indicadores Sociais Internos nas empresas, Usinas Itamarati S/A e Usina Barralcool S/A, conhecendo sobre a responsabilidade de cada uma das entidades para com seu público interno. Além de se tratar de entidades de grande porte do setor sucroenergético, as empresas publicam anualmente o Balanço Social modelo Ibase.

Diante do exposto, o objetivo da pesquisa foi responder a seguinte questão problema: Quais são os investimentos em Indicadores Sociais Internos na Usina Barralcool S/A em comparação com as Usinas Itamarati S/A nos anos de 2010 a 2012. Assim, objetivou-se especificam em identificar o percentual investido em Indicadores Sociais Internos com base nas receitas líquidas (RL) das empresas, apresentando uma análise comparativa dos Indicadores Sociais Internos e demonstrando em forma de rankings, os investimentos mais predominantes nas ações da entidade.

Justifica-se a elaboração desta pesquisa pelo aumento do interesse das empresas nas práticas relacionadas ao bem estar da sociedade e por se tratar de entidades responsáveis por grande parte da geração de emprego e renda de uma região, se torna válida uma avaliação que demonstre qual delas exerce maior esforço para o bem estar de seus funcionários.

\section{REFERENCIAL TEÓRICO}

\subsection{Responsabilidade Social Empresarial}

O conceito sobre Responsabilidade Social Empresarial tem como base, as questões éticas que envolvem a relação entre as empresas e a sociedade. Teve origem na década de 50, na Europa e nos Estados Unidos, graças a uma preocupação sobre a excessiva autonomia dos negócios empresariais e sua influência sobre a sociedade, sem que houvesse uma devida responsabilidade sobre as consequências negativas (BORGER, 2013).

Para Borger (2013), a evolução da responsabilidade social empresarial se relaciona com a filantropia empresarial, que surgiu para competir com outras formas de ações privadas para o bem da sociedade, porém, como filantropia se associa historicamente com caridade e assistência, cria um sentido negativo. $\mathrm{O}$ que deveria ser uma responsabilidade que fizesse parte da política da empresa acabava se confundindo como uma ação particular do empresário. 
Responsabilidade Social em uma empresa é um tema complexo, com diferentes formas de entendimento, podendo ser relacionada com responsabilidade legal, uma vez que caracteriza as empresas que cumprem as leis. Responsabilidade ética, as empresas que cumprem suas responsabilidades sociais além dos exigidos pela lei, e a responsabilidade discricionária, tomada pelas empresas que se interessam em realizar um papel social não obrigatório, ações essas julgadas e tomadas particularmente pelos empresários (BERTONCELLO; CHANG JUNIOR, 2007).

O formato mais comum de se conceituar a Responsabilidade Social é como a forma de gestão ética que a empresa exerce com todos os públicos que com ela se relaciona, efetuando sua atividade em compatibilidade com o desenvolvimento sustentável da sociedade (RICO, 2004). É preciso que haja preocupação da empresa para com a sociedade e não apenas com seu próprio crescimento econômico, pois quando se tem um crescimento econômico muito grande sem que haja também um desenvolvimento social, leva a um agravado capitalismo, empobrecendo a sociedade (CANDIL, 2010).

Para incentivar as empresas, a Assembléia Legislativa do Estado de Mato Grosso, através da Lei 7.687/02, criou o Certificado de Responsabilidade Social, de autoria dos deputados José Riva, Humberto Bosaipo e Eliene Lima. O certificado tem como objetivo, estimular a apresentação do Balanço Social pelas empresas, incentivar o reconhecimento dos esforços das empresas que buscam uma sociedade melhor, e promover debates sobre o tema Responsabilidade Social, propondo maior contribuição para o desenvolvimento sustentável do estado. As empresas que pretendem receber o certificado devem encaminhar o Balanço Social à Assembléia Legislativa até o dia 30 de Junho do ano seguinte ao demonstrado. Caberá a uma Comissão Mista o trabalho de organizar todo o processo de certificação (AL-MT).

\subsection{Balanço Social}

Há tempos as demonstrações contábeis das entidades tinham como principais interessados apenas seus gestores, mas com o passar do tempo, os credores também passaram a exigir informações quanto à capacidade da empresa de honrar suas dívidas. Com o surgimento e avanço das grandes empresas no século XVII e a necessidade dos investimentos, a contabilidade teve de aumentar seu leque de informações para prestar a seus usuários dados sobre o desempenho financeiro e econômico das entidades (TINOCO, 2006).

Após a Guerra do Vietnã, a população Norte Americana exigia que as empresas adotassem uma postura moral e ética perante os cidadãos. Então, a partir da década de 60, os funcionários passaram a exigir das empresas informações sobre seu desempenho econômico e 
social (TINOCO, 2006). No Brasil, já na década de 80, a estatal Nitrofértil foi à primeira empresa a divulgar o Balanço Social. O Balanço Social tornou-se mais evidente no país, graças ao sociólogo e ativista dos direitos humanos Hebert José de Souza, que criou em 1979 o Instituto Brasileiro de Análises Sociais e Econômicas - Ibase (DEGRAF, 2014)

O modelo Ibase de Balanço Social busca a padronização e expõem detalhadamente números referentes à responsabilidade social empresarial, contendo informações sobre gastos com folha de pagamento, encargos trabalhistas, participações nos lucros e resultado, gastos com controle ambiental e investimentos em áreas sociais internas e externas. Divide-se em 7 grupos, que são: Base de cálculo, Indicadores sociais internos, Indicadores sociais externos, Indicadores ambientais, Indicadores do corpo funcional, Informações relevantes quanto ao exercício da cidadania empresarial e Outras informações, todos apresentados em planilha única, o que facilita a consulta e entendimento dos interessados (LIMONGI et al., 2012).

O Balanço Social é uma demonstração contábil publicada anualmente, que tem a função de transmitir informações para os mais variados tipos de público de forma transparente, sobre os resultados econômicos, financeiros e sociais da entidade, reunindo diversos dados sobre projetos e investimentos em ações que beneficiam seu público interno e externo, servindo também de um grande instrumento estratégico para avaliação e multiplicação do seu comprometimento social (TORRES JUNIOR; SILVA, 2008). Qualquer que seja o valor investido pela entidade que promova a melhora na qualidade de vida humana, sócia e ecológica, cabe à apresentação no Balanço Social (KROETZ, 1999). É um relatório de dados que evidenciam qual o perfil da entidade na questão social durante o período, demonstrando questões sobre a relação da empresa com seus funcionários, o quanto foi investido para melhorar a qualidade das condições de trabalho, além de conter informações sobre a relação da empresa com a sociedade e o meio ambiente (IUDICIBUS; MARION, 2001).

Atualmente, o principal modelo de Balanço Social utilizado pelas entidades tem sido o modelo Ibase, uma vez que apresenta informações sistematizadas sobre seus investimentos internos e externos, permitindo uma fácil comparabilidade, com características simples e de fácil entendimento (TORRES; MANSUR, 2008). Para conhecimento do público foi demonstrado o Balanço Social modelo Ibase da Usina Barralcool S/A do ano de 2012 contendo dados sobre o pessoal interno da empresa e os investimentos realizados, conforme Quadro 1 a seguir.

Quadro 1: Balanço Social modelo Ibase ano 2012 - Usinas Barralcool S/A 


\begin{tabular}{|c|c|c|}
\hline \multicolumn{3}{|c|}{ MÉDIA E GRANDE EMRPESA } \\
\hline \multicolumn{3}{|c|}{1 - Mensagem do Presidente } \\
\hline \multicolumn{3}{|c|}{$\begin{array}{l}\text { A Usina Barralcool S/A valoriza e respeita a diversidade interna e externamente, firmando compromisso com a ética e a responsabilidade } \\
\text { social demonstrado através de seu Balanço Social de 2012; a empresa declara que não utiliza mão-de-obra infantil, trabalho degradante e } \\
\text { análogo à escravidão, não tem envolvimento com prostituição ou exploração sexual infantil ou adolescente e não está envolvida com } \\
\text { corrupção. }\end{array}$} \\
\hline \multicolumn{3}{|c|}{ IDENTIFICACC̃̃O } \\
\hline \multicolumn{3}{|c|}{$\begin{array}{l}\text { RAZÃO OU DENOMINAÇÃO SOCIAL: USINA BARRALCOOL S/A } \\
\text { ENDEREÇO: ROD. MT } 246 \text { km 3,5 S/N - DIST. INDULTRIAL - BARRA DO BUGRES - MT - CEP: 78390-000 } \\
\text { CNPJ: 33.664.228/0001-35 } \\
\text { RAMO DE ATIVIDADE: FABRICAÇÃO DE AÇÚCAR, ÁLCOOL, ENERGIA E BIODIESEL }\end{array}$} \\
\hline \multirow{2}{*}{ INDICADORES ECONOMICOS } & 2012 & 2011 \\
\hline & Valores (mil reais) & Valores (mil reais) \\
\hline RECEITA LIQUIDA & 275.711 & 300.815 \\
\hline RESULTADO OPERACIONAL & 7.334 & 53.215 \\
\hline FOLHA DE PAGAMENTO BRUTA & 24.243 & 28.424 \\
\hline \multicolumn{3}{|c|}{ INDICADORES SOCIAIS } \\
\hline \multirow{2}{*}{ AMBIENTE INTERNO } & 2012 & 2011 \\
\hline & Valores (mil reais) & Valores (mil reais) \\
\hline Alimentação & 2.544 & 2.365 \\
\hline Saúde & 378 & 351 \\
\hline Segurança e Medicina do Trabalho & 450 & 322 \\
\hline Capacitação e Desenvolvimento Profissional & 58 & 111 \\
\hline Creche ou Auxílio Creche & 1 & 0 \\
\hline Previdência Privada & 0 & 0 \\
\hline Educação e Cultura & 1 & 3 \\
\hline Participação nos Lucros e Resultados & 963 & 393 \\
\hline Outros Benefícios & 97 & 1.150 \\
\hline Total & 4.492 & 4.695 \\
\hline \multicolumn{3}{|c|}{ CORPO FUNCIONAL } \\
\hline Total Geral de Empregados em 31/12 & 1.478 & 952 \\
\hline Total de Admissões & 980 & 878 \\
\hline Total de Demissões & 454 & 939 \\
\hline Total de Estagiários em 31/12 & 0 & 20 \\
\hline Total de Empregados portadores de necessidades especiais & 14 & 16 \\
\hline Total de Prestadores de Serviços Terceirizados em 31/12 & 83 & 260 \\
\hline Total de Empregados por Sexo & $\begin{array}{l}\text { Feminino: } 102 \\
\text { Masculino: } 1.376 \\
\end{array}$ & \begin{tabular}{|l|} 
Feminino: 81 \\
Masculino: 871 \\
\end{tabular} \\
\hline Total de Empregados por faixa etária & $\begin{array}{l}\text { Menores de } 18 \text { Anos: } 0 \\
18 \text { a } 45 \text { Anos: } 1246 \\
\text { Acima de } 45 \text { anos: } 232\end{array}$ & $\begin{array}{l}\text { Menores de } 18 \text { anos: } 0 \\
18 \text { a } 45 \text { anos: } 754 \\
\text { Acima de } 45 \text { anos: } 198\end{array}$ \\
\hline Total de Empregados por Nível de Escolaridade & \begin{tabular}{|l} 
Analfabetos: 0 \\
Ensino Fundamental: 590 \\
Ensino Médio: 744 \\
Ensino Técnico: 47 \\
Ensino Superior: 81 \\
Pós Graduação: 16 \\
\end{tabular} & \begin{tabular}{|l|} 
Analfabetos: 0 \\
Ensino Fundamental: 471 \\
Ensino Médio: 427 \\
Ensino Técnico: 36 \\
Ensino Superior: 71 \\
Pós Graduação: 8 \\
\end{tabular} \\
\hline Total Cargos de Chefia, por Sexo & $\begin{array}{l}\text { Feminino: } 102 \\
\text { Masculino: } 97\end{array}$ & \begin{tabular}{|l|} 
Feminino: 7 \\
Masculino: 89
\end{tabular} \\
\hline
\end{tabular}

Fonte: Adaptado Balanço Social (2012), Usina Barralcool S/A.

O modelo Ibase, como demonstrado, agrega várias informações de natureza social, contendo informações sobre índices escolares, empregados por sexo, empregados por faixa etária, sendo de fácil entendimento mesmo para as pessoas que não tem conhecimento na área contábil. O Balanço torna público relevante informações para qualquer tipo de usuário das informações, entre eles, funcionários, governos e investidores.

\subsection{Indicadores Sociais Internos}

Conceitua - se Indicadores Sociais como uma medida quantitativa, com significado social. É uma metodologia que tem por finalidade informar aspectos sobre a realidade social 
ou mudanças que estão em desenvolvimento. Os indicadores ajudam no planejamento, monitoramento e investigação das condições de vida e bem-estar da população, auxiliando no desenvolvimento de práticas para melhorias sociais (JANNUZZI, 2002).

No âmbito empresarial, os indicadores sociais internos são identificados como os investimentos da empresa, para beneficiar seus funcionários e seus dependentes ou aposentados. As formas mais comuns de indicadores sociais internos das empresas são os investimentos feitos em Alimentação (Cestas básicas, gastos com restaurante, vale-refeição e lanches), Saúde (Programas de prevenção à doenças, planos de saúde, plano odontológico, programas de qualidade de vida, entre outros gastos com saúde), Educação e Cultura (Gastos em ensino, bolsas de estudos, gastos com eventos artísticos e culturais), Capacitação e Desenvolvimento Profissional (Treinamentos, cursos e estágios), Participação dos Lucros e Resultados - PLR (Incentiva o funcionário por meio de bonificação paga relativamente ao desempenho da empresa), Segurança e Medicina do Trabalho (EPI's, equipamentos para prevenção de acidentes de trabalho), Previdência Privada (Planos de aposentadoria e complementação de benefícios à aposentados) e Outros Benefícios (SANTOS, 2012).

Outros benefícios são os investimentos feitos pelas empresas em diversas áreas, como seguro de vida, estacionamento gratuito, transportes gratuitos, vendas de produtos fabricados pela empresa com desconto para os funcionários, alojamentos, assistência social, horários flexíveis, dentre outras formas que variam de empresa para empresa, tendo sempre o intuito de beneficiar seu público interno (CASTRO; SILVA FILHO, 2011).

Os indicadores observados no Balanço Social expressam o compromisso da empresa com o desenvolvimento profissional e a qualidade de vida de seus funcionários, visto que revela a harmonia da relação organização e colaboradores, demonstrando que o lucro de uma empresa é pertencente a vários grupos de interesse (TAIAROL; RAIMUNDINI; BEHR, 2011).

Observa-se que há um consenso entre todos os autores sobre os temas tratados, e que além de ser importante haver nas empresas maior responsabilidade perante a sociedade, também se faz valoroso a publicação do Balanço Social, demonstrando seus empenhos em contribuir para a melhoria social.

\section{METODOLOGIA}

Segundo Gerhardt e Silveira (2009), é indispensável o uso de métodos e procedimentos para desenvolver qualquer estudo. Esta pesquisa tem natureza descritiva, e 
utilizou de procedimentos documentais e bibliográficos, visto que analisou dados secundários contidos em Balanços Sociais das empresas estudadas. Pesquisa documental recorre a fontes para tratamento analítico como, tabelas estatísticas, relatório de empresas, sites etc., diferente da bibliográfica que consiste em buscar fontes constituídas por livros e artigos científicos (FONSECA, 2002). Dados secundários consistem em atribuir informações existentes em fontes variadas, podendo ser recolhidas e analisadas, produzindo conhecimento (SOUZA; OLIVEIRA; SILVA JUNIOR, 2013).

A pesquisa pode ser caracterizada como um estudo de caso, modalidade que busca conhecer profundamente uma situação, buscando seus aspectos, possibilitando que o pesquisador divulgue certas condições, sem alterar o objeto estudado, se adequando ao proposto pela pesquisa (FONSECA, 2002). Foi utilizada abordagem quantitativa, consistindo em analisar dados, recorrendo à matemática para descrever fenômenos, possibilitando o alcance dos objetivos em menor tempo. Tem suas teorias e hipóteses definidas de forma rigorosa, e utiliza de instrumentos para buscar dados (GERHARDT; SILVEIRA, 2009).

Foram analisados dados acerca da Receita Líquida (RL) das empresas, também todos os itens contidos na categoria indicadores sociais internos, definidos pelos investimentos das empresas em alimentação, saúde, segurança e medicina do trabalho, capacitação e desenvolvimento profissional, creches e auxílio-creche, previdência privada, educação e cultura, participação nos lucros e resultados e outros benefícios (SANTOS, 2012).

Foram utilizadas tabelas e quadros, que demonstraram os percentuais e as mutações ocorridas nos investimentos. Para se calcular os valores e obter os dados que possibilitassem a comparação entre os dados foi utilizado o software Microsoft Excel. Assim o próximo item apresenta os resultados obtidos e as discussões sobre os mesmos.

\section{RESULTADOS E DISCUSSÕES}

Esta seção apresenta todos os resultados obtidos através da pesquisa, alcançando os objetivos propostos através de análise vertical, horizontal e quadros que analisaram individualmente os investimentos médios por funcionários. $\mathrm{O}$ objeto desse estudo, trata-se da Usinas Itamarati S/A, sediada no município de Nova Olímpia - MT e a Usina Barralcool S/A, sediada na cidade Barra do Bugres - MT. A distância entre a localização das empresas é de 40 $\mathrm{km}$.

No Quadro 2 é apresentado a quantidade de funcionários ativos, as receitas líquidas e os investimentos realizados nos indicadores sociais pela Usinas Itamarati S/A. 
Quadro 2 - Resultados da Usinas Itamarati S/A no período de 2010 a 2012

\begin{tabular}{|c|c|c|c|}
\hline Período & Funcionários & Receita Líquida & Investimento \\
\hline 2010 & 2.965 & $\mathrm{R} \$ 647.278 .000,00$ & $\mathrm{R} \$ 25.758 .000,00$ \\
\hline 2011 & 2.780 & $\mathrm{R} \$ 597.776 .000,00$ & $\mathrm{R} \$ 23.401 .000,00$ \\
\hline 2012 & 2.999 & $\mathrm{R} \$ 589.636 .000,00$ & $\mathrm{R} \$ 25.081 .000,00$ \\
\hline
\end{tabular}

Fonte: Adaptado Balanço Social (2010 a 2012), Usinas Itamarati S/A.

Os dados apresentam queda nas Receitas Líquidas da Usinas Itamarati S/A. De 2010 a 2012 a empresa teve diminuição de $\mathrm{R} \$ 57.642 .000,00$ em sua receita, representando queda de 8,90\% mesmo com um número maior de funcionários em 2012. Observa-se que seus investimentos não diminuíram proporcionalmente à Receita Líquida, apresentando diminuição de $\mathrm{R} \$ 677.000,00$ de 2010 a 2012, o que representou queda de 2,63\% apenas. Conforme análise, mesmo mantendo os investimentos em grandes alterações e aumentando o número de funcionário, a empresa diminuiu suas receitas.

Por outro lado, no Quadro 3 apresentou, por período, a quantidade de funcionários ativos, as receitas líquidas e os investimentos realizados nos indicadores sociais pela Usina Barralcool S/A.

Quadro 3 - Resultados da Usina Barralcool S/A no período de 2010 a 2012

\begin{tabular}{|c|c|c|c|}
\hline Período & Funcionários & Receita Líquida & Investimento \\
\hline 2010 & 1.013 & $267.987 .301,00$ & $4.830 .125,00$ \\
\hline 2011 & 952 & $300.815 .225,00$ & $4.695 .171,00$ \\
\hline 2012 & 1.478 & $275.711 .000,00$ & $4.492 .000,00$ \\
\hline
\end{tabular}

Fonte: Adaptado Balanço Social (2010 a 2012), Usina Barralcool S/A.

Em análise ao quadro, identifica-se, ao contrário da Usinas Itamarati S/A, bons resultados para a Usina Barralcool. O ano de 2010 comparado a 2012, a empresa obteve um resultado positivo em suas receitas de $\mathrm{R} \$ 7.723 .699,00$, equivalente a aumento de $2,88 \%$. Quanto aos seus investimentos em benfeitorias internas a empresa investiu menos com o passar dos anos, o que é um bom resultado, pois investiu menos e aumentou sua receita. $\mathrm{O}$ ano de 2011 foi período com menor número de funcionários e o de maior Receita Líquida.

Foram utilizadas tabelas para demonstrar os percentuais investidos em indicadores sociais com base nas receitas líquidas e as mutações ocorridas em cada período. Identificou-se o investimento nos indicadores ano a ano, facilitando a comparabilidade dos dados, como consta na análise vertical apresentada a seguir.

Tabela 1 - Análise vertical dos indicadores sociais internos em relação à receita líquida (Usinas Itamarati S/A e Usina Barralcool S/A) 


\begin{tabular}{lccccccc}
\hline \multicolumn{1}{c}{ ITEM } & \multicolumn{2}{c}{ Usinas Itamarati S/A } & \multicolumn{2}{c}{ Usina Barralcool S/A } \\
& $\mathbf{2 0 1 0}$ & $\mathbf{2 0 1 1}$ & $\mathbf{2 0 1 2}$ & $\mathbf{2 0 1 0}$ & $\mathbf{2 0 1 1}$ & $\mathbf{2 0 1 2}$ \\
\hline Receita Operacional Líquida & $\mathbf{1 0 0}$ & $\mathbf{1 0 0}$ & $\mathbf{1 0 0}$ & $\mathbf{1 0 0}$ & $\mathbf{1 0 0}$ & $\mathbf{1 0 0}$ \\
Alimentação & 0,85 & 0,93 & 1,00 & 0,74 & 0,79 & 0,92 \\
Saúde & 0,54 & 0,51 & 0,52 & 0,13 & 0,12 & 0,14 \\
Segurança e Medicina do Trabalho & 0,34 & 0,37 & 0,45 & 0,17 & 0,11 & 0,16 \\
Capacitação e Desenvolvimento Profissional & 0,03 & 0,08 & 0,07 & 0,02 & 0,04 & 0,02 \\
Creche ou Auxílio Creche & & & & & & & \\
Previdência Privada & 0,00 & 0,00 & 0,00 & 0,00 & 0,00 & 0,00 \\
Educação e Cultura & 0,00 & 0,00 & 0,00 & 0,00 & 0,00 & 0,00 \\
Participação nos Lucros e Resultados & 0,02 & 0,01 & 0,00 & 0,01 & 0,00 & 0,00 \\
Outros Benefícios & 0,37 & 0,38 & 0,47 & 0,10 & 0,13 & 0,35 \\
\hline Total Investido & 1,82 & 1,64 & 1,73 & 0,63 & 0,38 & 0,04 \\
\hline
\end{tabular}

Fonte: Adaptado Balanço Social (2010 a 2012), Usinas Itamarati S/A e Usina Barralcool S/A.

Em análise à Tabela 1, observa-se que a Usinas Itamarati S/A apresentou notável representatividade nos investidos em outros benefícios. Situação similar foi observada em pesquisa realizada por Santos (2012), analisando os dados dos anos de 2008 a 2010, demonstrou que o maior investimento se deu no mesmo item. Em relação à Usina Barralcool S/A, o maior investimento foi em alimentação, fato semelhante foi observado no período estudado pela referida autora.

Foram analisadas as mutações ocorridas nos períodos, evidenciando as melhorias e as quedas dos indicadores nos anos em estudo, conforme demonstrado.

Tabela 2 - Análise Horizontal das evoluções dos investimentos em indicadores sociais internos. (Usinas Itamarati S/A e Usina Barralcool) 


\begin{tabular}{lcccccc}
\hline \multirow{2}{*}{ ITEM } & \multicolumn{3}{c}{ Usinas Itamarati S/A } & \multicolumn{3}{c}{ Usina Barralcool S/A } \\
& $\mathbf{2 0 1 0}$ & $\mathbf{2 0 1 1}$ & $\mathbf{2 0 1 2}$ & $\mathbf{2 0 1 0}$ & $\mathbf{2 0 1 1}$ & $\mathbf{2 0 1 2}$ \\
\hline Receita Operacional Líquida & $100 \%$ & $-7,65$ & $-1,36$ & $100 \%$ & 12,25 & $-8,35$ \\
\hline Alimentação & & & & & \\
Saúde & $100 \%$ & $-0,04$ & 6,45 & $100 \%$ & 19,76 & 7,53 \\
Segurança e Medicina do Trabalho & $100 \%$ & $-13,09$ & 0,92 & $100 \%$ & $-3,13$ & 7,89 \\
Capacitação e Desenvolvimento Profissional & $100 \%$ & 0,36 & 20,54 & $100 \%$ & $-28,85$ & 40,10 \\
Creche ou Auxílio Creche & $100 \%$ & 174,85 & $-6,97$ & $100 \%$ & 99,80 & $-47,82$ \\
Previdência Privada & $100 \%$ & 0,00 & 77,78 & $100 \%$ & 0,00 & 0,00 \\
Educação e Cultura & $100 \%$ & 0,00 & 0,00 & $100 \%$ & 0,00 & 0,00 \\
Participação nos Lucros e Resultados & $100 \%$ & $-63,87$ & $-51,16$ & $100 \%$ & $-84,01$ & $-67,35$ \\
Outros Benefícios & $100 \%$ & $-4,84$ & 20,62 & $100 \%$ & 44,77 & 144,76 \\
Total Investido & $100 \%$ & $-17,03$ & 4,24 & $100 \%$ & $-32,15$ & $-91,57$ \\
\hline
\end{tabular}

Fonte: Adaptado Balanço Social (2010 a 2012), Usinas Itamarati S/A e Usina Barralcool S/A.

A tabela 2 apresentou as mutações dos investimentos feitos pelas empresas. Na Usinas Itamarati S/A, as quedas mais expressivas se deram nos investimentos em educação e cultura, que diminuiu continuamente nos períodos. Os melhores avanços foram nos itens capacitação e desenvolvimento profissional em 2011, segurança e medicina do trabalho em 2012 e participação dos lucros e resultados em 2012.

Foi possível evidenciar resultados positivos na Usina Barralcool S/A, com expressividade nos itens alimentação, capacitação e desenvolvimento profissional e na participação dos lucros e resultados. Os piores resultados foram em educação e cultura e no item outros benefícios.

Para uma comparação entre os investimentos das empresas, foram analisadas as médias de investimentos por funcionário em cada um dos indicadores sociais. Deste modo, foram desenvolvidos quadros contendo o período de referência e a média de investimento de cada empresa, conforme resultados apresentados no Quadro 4 a seguir.

Quadro 4 - Média de investimento por funcionário em alimentação

\begin{tabular}{|c|c|c|}
\hline Período & Usinas Itamarati S/A & Usina Barralcool S/A \\
\hline 2010 & $1.866,10$ & $1.950,13$ \\
\hline 2011 & $1.989,57$ & $2.485,11$ \\
\hline 2012 & 1963,32 & $1.721,24$ \\
\hline
\end{tabular}

Fonte: Adaptado Balanço Social (2010 a 2012), Usinas Itamarati S/A e Usina Barralcool S/A.

Observou-se que nos anos 2010 e 2011 a Usina Barralcool S/A apresentou maiores investimentos no item em questão, reduzindo-os em 2012, onde a Usinas Itamarati S/A atingiu maior resultado. A Usinas Itamarati manteve estabilidade nos investimentos, ao contrário da Usina Barralcool, que apresentou grandes oscilações nos períodos.

Os resultados da pesquisa de Santos (2012) demonstraram que os investimentos da Usina Barralcool foram superiores em todos os períodos estudados, chegando a atingir 
investimento de $\mathrm{R} \$ 4.596,93$ por funcionário em 2008. A autora relaciona as mutações ocorridas com a quantidade de empregados em cada período.

A média de investimentos por funcionário no item saúde pode ser analisada, conforme demonstrado no Quadro 5.

Quadro 5 - Média de investimento por funcionário em saúde

\begin{tabular}{|c|c|c|}
\hline Período & Usinas Itamarati S/A & Usina Barralcool S/A \\
\hline 2010 & $1.187,52$ & 357,04 \\
\hline 2011 & $1.100,72$ & 368,03 \\
\hline 2012 & $1.029,68$ & 255,75 \\
\hline
\end{tabular}

Fonte: Adaptado Balanço Social (2010 a 2012), Usinas Itamarati S/A e Usina Barralcool S/A.

A Usinas Itamarati S/A obteve maiores investimentos em saúde, em todos os anos estudados. Os resultados da pesquisa de Santos (2012) confirmam que a Usinas Itamarati S/A manteve maiores investimentos em relação a Usina Barralcool S/A. Notou-se decréscimos nos investimentos da Usina Barralcool S/A com o passar dos anos, perfazendo em 2008 o valor de $\mathrm{R} \$ 680,38$ por funcionário e finalizando 2012 com apenas $\mathrm{R} \$ 255,75$ em média.

Foi observada ainda, a média de investimentos em segurança e medicina do trabalho, conforme apresentado no Quadro 6.

Quadro 6 - Média de investimento por funcionário em segurança e medicina do trabalho

\begin{tabular}{|c|c|c|}
\hline Período & Usinas Itamarati S/A & Usina Barralcool S/A \\
\hline 2010 & 747,62 & 445,65 \\
\hline 2011 & 800,36 & 337,40 \\
\hline 2012 & 894,30 & 304,47 \\
\hline
\end{tabular}

Fonte: Adaptado Balanço Social (2010 a 2012), Usinas Itamarati S/A e Usina Barralcool S/A.

Os investimentos mais expressivos em segurança e medicina do trabalho foram realizados pela Usinas Itamarati S/A, mantendo resultados crescentes nos períodos. Em contrapartida, a Usina Barralcool apresentou diminuição progressiva. Foi relevante destacar, que a pesquisa de Santos (2012) evidenciou que o aumento nos investimentos da Usinas Itamarati S/A, tem ocorrido de forma contínua desde 2008.

Os investimentos médios em capacitação e desenvolvimento profissional, se desenvolveram como demonstrado no quadro 7.

Quadro 7 - Média de investimento por funcionário em capacitação e desenvolvimento profissional

\begin{tabular}{|c|c|c|}
\hline Período & Usinas Itamarati S/A & Usina Barralcool S/A \\
\hline 2010 & 56,32 & 54,92 \\
\hline 2011 & 165,11 & 116,76 \\
\hline 2012 & 142,38 & 39,24 \\
\hline
\end{tabular}

Fonte: Adaptado Balanço Social (2010 a 2012), Usinas Itamarati S/A e Usina Barralcool S/A. 
Os investimentos, quando confrontados à anos anteriores aos abordados nesta pesquisa, foram superiores. Segundo Santos (2012), em 2008 a Usinas Itamarati S/A investiu $\mathrm{R}$ \$ 105,64, em contrapartida a Usina Barralcool S/A apenas R 24,12 por funcionário, comprovando que houve evolução nos investimentos das empresas no item capacitação e desenvolvimento profissional. Se comparadas, a Usinas Itamarati S/A foi superior em todos os períodos, chegando a $\mathrm{R} \$ 142,38$ por funcionário em 2012, enquanto a Usina Barralcool S/A com queda brusca no período, com apenas $\mathrm{R} \$ 39,24$.

Quadro 8 - Média de investimento por funcionário em educação e cultura

\begin{tabular}{|c|c|c|}
\hline Período & Usinas Itamarati S/A & Usina Barralcool S/A \\
\hline 2010 & 40,13 & 18,91 \\
\hline 2011 & 15,47 & 3,22 \\
\hline 2012 & 7,00 & 0,68 \\
\hline
\end{tabular}

Fonte: Adaptado Balanço Social (2010 a 2012), Usinas Itamarati S/A e Usina Barralcool S/A.

O indicador educação e cultura se destaca pelo baixo investimento recebido pelas empresas. Ao analisar dados da pesquisa de Santos (2012), é possível conferir a redução dos investimentos desde 2008. A autora justifica tal situação pelo fato das empresas investirem em projetos paralelos. Como é o caso do projeto Doce Vida desenvolvido pela Usina Barralcool S/A, com atividades educativas, esportivas e culturais para crianças. A Usina $s$ Itamarati S/A investe em projetos educativos e culturais, como o Estrelas de Nova Olímpia que ensina artes marciais para as crianças, e o projeto de Bem com a Vida que visa afastar e alertar as pessoas sobre o mundo das drogas. Todos esses projetos agregam os itens educação e cultura.

A análise dos dados possibilitou a demonstração do investimento médio em participação dos lucros e resultados, conforme apresentados no quadro 9.

Quadro 9 - Média de investimento por funcionário em participação dos lucros e resultados (PLR)

\begin{tabular}{|c|c|c|}
\hline Período & Usinas Itamarati S/A & Usina Barralcool S/A \\
\hline 2010 & 807,76 & 268,27 \\
\hline 2011 & 819,78 & 413,28 \\
\hline 2012 & 916,64 & 651,56 \\
\hline
\end{tabular}

Fonte: Adaptado Balanço Social (2010 a 2012), Usinas Itamarati S/A e Usina Barralcool S/A.

Os valores depositados em PLR dependem dos resultados obtidos pelas empresas, portanto se o lucro é maior, também será a quantia investida. A Usinas Itamarati S/A superou a Usina Barralcool S/A em todos os períodos. Sobre a Usina Barralcool S/A, foi constatado na pesquisa de Santos (2012), que não houve investimentos em PLR nos anos de 2008 e 2009, 
somente a partir de 2010, passando a aumentar progressivamente suas receitas líquidas, e consequentemente aplicando mais em PLR.

O indicador outros benefícios somou grandes quantias nos períodos, em especial na Usinas Itamarati S/A, como apresentado a seguir no quadro 10.

Quadro 10 - Média de investimento por funcionário em outros benefícios

\begin{tabular}{|c|c|c|}
\hline Período & Usinas Itamarati S/A & Usina Barralcool S/A \\
\hline 2010 & $3.981,79$ & $1.673,23$ \\
\hline 2011 & $3.523,38$ & $1.208,10$ \\
\hline 2012 & $3.404,47$ & 65,63 \\
\hline
\end{tabular}

Fonte: Adaptado Balanço Social (2010 a 2012), Usinas Itamarati S/A e Usina Barralcool S/A.

Ao observar o investimento médio por funcionário feito pelas empresas no item outros benefícios, foram evidentes, além da superioridade da Usinas Itamarati, haver decréscimos no investimento das duas empresas com o passar dos períodos, porém mais relevante para a Usina Barralcool S/A, finalizando 2012 com apenas R\$ 65,63 por funcionário. O estudo de Silva (2012) demonstra que a Usinas Itamarati S/A vem diminuindo seus investimentos no item, pois chegou a $\mathrm{R} \$ 5.205,67$ por funcionário em 2008, diminuindo ano a ano.

Nos itens Previdência Privada e Creche e Auxílio Creche houve pouco investimento por parte das empresas, não chegando a $0,01 \%$ da RL, irrelevantes para a comparação. Em estudo realizado por Santos (2012), a situação foi similar, não havendo representatividade nesses indicadores.

A seguir é apresentado no quadro 11, o Ranking dos investimentos da Usinas Itamarati S/A e da Usina Barralcool S/A, percebendo quais foram os itens que mais se destacaram e mantém prioridade nas empresas.

Quadro 11 - Ranking dos investimento em indicadores sociais internos

\begin{tabular}{|l|l|c|l|}
\hline \multicolumn{2}{|c|}{ Usinas Itamarati S/A } & \multicolumn{2}{c|}{ Usina Barralcool S/A } \\
\hline $\mathbf{1}^{\circ}$ & Outros Benefícios & $\mathbf{1}^{\circ}$ & Alimentação \\
\hline $\mathbf{2}^{\circ}$ & Alimentação & $\mathbf{2}^{\circ}$ & Outros Benefícios \\
\hline $\mathbf{3}^{\circ}$ & Saúde & $\mathbf{3}^{\circ}$ & Participação nos Lucros e Resultados \\
\hline $\mathbf{4}^{\circ}$ & Participação nos Lucros e Resultados & $\mathbf{4}^{\circ}$ & Segurança e Medicina do Trabalho \\
\hline $\mathbf{5}^{\circ}$ & Segurança e Medicina do Trabalho & $\mathbf{5}^{\circ}$ & Saúde \\
\hline $\mathbf{6}^{\circ}$ & Capacitação e Desenvolvimento Profissional & $\mathbf{6}^{\circ}$ & Capacitação e Desenvolvimento Profissional \\
\hline $\mathbf{7}^{\circ}$ & Educação e Cultura & $\mathbf{7}^{\circ}$ & Educação e Cultura \\
\hline
\end{tabular}




\begin{tabular}{|l|l|c|l|} 
& Creche e Auxílio Creche & $\mathbf{8}^{\circ}$ & Creche e Auxílio Creche \\
\hline $\mathbf{9}^{\circ}$ & Previdência Privada & $\mathbf{9}^{\circ}$ & Previdência Privada \\
\hline
\end{tabular}

Fonte: Adaptado Balanço Social (2010 a 2012), Usinas Itamarati S/A e Usina Barralcool S/A.

Como demonstrado, cada empresa tem prioridades diferentes quando investem em indicadores internos. No caso, a Usinas Itamarati S/A mantém seus maiores investimentos em outros benefícios, alimentação e saúde. Em contrapartida, a Usina Barralcool S/A concentra seus maiores investimentos em alimentação, outros benefícios e participação dos lucros e resultados.

\section{CONSIDERAÇÕES FINAIS}

Em resposta à questão problema proposta, identificar quais são os investimentos internos da Usinas Itamarati S/A em comparação com a Usina Barralcool S/A, observou-se que se tratando do montante geral investido, não houve um aumento progressivo, pois as duas empresas tiveram uma diminuição no investimento de 2010 para 2011. Houve aumento de 2011 para 2012 nas Usinas Itamarati S/A, por outro lado a Usina Barralcool obteve aumento no investimento total se comparado à sua receita, porém decréscimo se comparado ao ano anterior. As maiores alterações se deram pela diversificação de investimentos das empresas, diminuindo em alguns itens, ao mesmo tempo em que aumentou em outros com o passar dos anos, fazendo com que não houvesse grandes alterações na média total investida dos anos.

Com base no primeiro objetivo específico, que foi identificar os investimentos em indicadores com base nas receitas líquidas, foi elaborado tabelas através de dados contidos nos balanços sociais das empresas, que demonstraram verticalmente os percentuais investidos e horizontalmente as mutações ocorridas.

Quanto ao segundo objetivo, apresentar uma análise comparativa dos investimentos em indicadores, foram elaborados quadros que analisaram as quantias atribuídas aos indicadores, calculando a média investida por funcionário ativo na empresa em cada período. Essa análise evidenciou que a Usinas Itamarati S/A foi superior em todos os investimentos, exceto no item alimentação em 2010 e 2011.

O terceiro objetivo específico, demonstrar o ranking dos investimentos, demonstrou em quadro, os nove indicadores existentes nas empresas, evidenciando em cadeia, quais os indicadores que possuem prioridade nas empresas e os que receberam menos investimentos.

Os resultados demonstraram que a Usinas Itamarati S/A mantiveram um índice mais estabilizado, com um pequeno decréscimo de 2010 para 2011 e um aumento de 2011 para 
2012, superando os valores do primeiro ano demonstrado. A Usina Barralcool S/A obteve a mesma estabilidade, tendo um decréscimo de 2010 para 2011 e um aumento de 2011 para 2012, mas não foi superado o primeiro ano analisado.

Em comparação com estudo realizado por Santos (2012), foi possível observar as evoluções das empresas desde o ano de 2008 na parte de responsabilidade social interna. Verificou-se que em 2008 a Usinas Itamarati S/A investiu 5,92\% de sua RL, terminando 2012 com investimento de $4,25 \%$, ou seja, não manteve um padrão crescente ou estabilizado. Em contrapartida, a Usina Barralcool S/A investiu em 2008, um total de 1,52\% de sua RL em indicadores Internos, terminando 2012 com 1,63\%, sempre mantendo uma margem de investimento sem grandes oscilações.

Portanto, para a pesquisa, o mais adequado seria o uso de dados atualizados, porém até o período do desenvolvimento da pesquisa, a Usinas Itamarati S/A não publicou seu Balanço Social. Ainda assim foi possível obter informações relevantes para o público interessado, uma vez que para se informar sobre as condições das empresas, o público teria que buscar essas publicações, por serem as mais atuais disponíveis.

Por fim, como sugestão para trabalhos futuros, seria relevante a elaboração de outras pesquisas, que demonstrassem os investimentos feitos pelas empresas voltados para a questão social, auxiliando na conscientização do público, o que de certa maneira coagiria as empresas a aumentar seus esforços pelo o bem estar da sociedade e, consequentemente, às demonstrando por meio do Balanço Social. Outra sugestão seria a elaboração de estudos que verificassem quais as mudanças ocorridas na empresa quando investem mais no bem estar dos funcionários.

\section{REFERÊNCIAS}

AL-MT. Assembléia Legislativa do Estado de Mato Grosso. Lei $\mathrm{n}^{\circ}$ 8.477, de 15 de maio de 2006. Disponível em: <http://www.al.mt.gov.br/conteudo/institucional/anexos/Lei-8477.pdf> Acesso em: 02 Maio 2015.

BALANÇO SOCIAL. Usinas Itamarati S/A, 2010. Disponível em: <http://www.usinasitamarati.com.br/itamarati/elementos/relatorio2010/pdfs/14_balanco_socia 1.pdf>. Acesso em: 15 Outubro 2014.

Usinas Itamarati S/A, 2011. Disponível em: <http://www.usinasitamarati.com.br/itamarati/elementos/relatorio2011/pdfs/13balancosocial.p df $>$. Acesso em: 15 Outubro 2014. 
Usinas Itamarati S/A, 2012. Disponível em:

<ww.usinasitamarati.com.br/itamarati/elementos/.../13balancosocial.pdf >. Acesso em: 15 Outubro 2014.

BALANÇO SOCIAL. Usina Barralcool S/A, 2006 a 2013. Disponível em: <http://www.al.mt.gov.br/conteudo/institucional/resp-social-balancos-2006-2013.php>. Acesso em: 11 Setembro 2014.

BERTONCELLO, S. L. T.; CHANG JUNIOR, J. A importância da responsabilidade social corporativa como fator de diferenciação. Revista da Faculdade de Comunicação FAAP (FACOM), v. 17, 70-76. São Paulo, 2007. Disponível em: <www.faap.br/revista_faap/revista_facom/facom_17/silvio.pdf >. Acesso em: 12 Outubro 2014.

BORGER, F. G. Responsabilidade social empresarial e sustentabilidade para gestão empresarial. Instituto Ethos, 2013. Disponível em:

$<$ http://www3.ethos.org.br/cedoc/responsabilidade-social-empresarial-e-sustentabilidadepara-a-gestao-empresarial>. Acesso em: 13 Novembro 2014.

CANDIL, S. L. Responsabilidade social empresarial: diretrizes e parâmetros da racionalidade econômica e jurídica. Marília: UNIMAR, 2010. Disponível em: < http://www.unimar.br/pos/trabalhos/arquivos/88C937DEE5E107A3A82D4EE9B4D60C64. pdf>. Acesso em: 30 Novembro 2014.

CASTRO, J. E. G; SILVA FILHO, J. C. L. Análise de indicadores sociais e ambientais de uma empresa de serviços de logística: um estudo de caso da ALL no período de 2003 a 2008.

GEPROS: Gestão da Produção, Operações e Sistemas, Ano 6, n³, p. 41-58, 2011. Disponível em: <http://revista.feb.unesp.br/index.php/gepros/article/viewFile/575/356>. Acesso em: 12 Novembro 2014.

DALFOVO, M. S; LANA, R, A; SILVEIRA, A. Métodos quantitativos e qualitativos: um resgate teórico. Revista Interdisciplinar Científica Aplicada, Blumenau, v.2, n.4, p.01-13, 2008. Disponível em:

<http://www.unisc.br/portal/upload/com_arquivo/metodos_quantitativos_e_qualitativos_um_r esgate_teorico.pdf >. Acesso em: 13 Setembro 2014.

DEGRAF, E. Contabilidade em pauta: balanço social. Faculdade Santa Cruz, 2014. Disponível em: < http://www.santacruz.br/v4/download/contabilidade-em-pauta/balancosocial.pdf $>$. Acesso em: 27 Maio 2015.

FERREIRA, A. C. S. et al. Contabilidade ambiental e relatórios sociais. São Paulo: Editora Atlas, 2009.

FERRER, W. M. H. Metodologia da pesquisa científica: Orientações quanto à elaboração e apresentação gráfica do Projeto de Pesquisa e do Trabalho de Conclusão de Curso. Marília: UNIMAR, 2012. Disponível em: <www.unimar.br/publicacoes/2010/manual_direito.pdf>. Acesso em: 30 Agosto 2014. 
FONSECA, J. J. S. Metodologia da pesquisa científica. Fortaleza: UEC, 2002. Disponível em: <http://www.ia.ufrrj.br/ppgea/conteudo/conteudo-20121/1SF/Sandra/apostilaMetodologia.pdf>. Acesso em: 01 setembro 2014.

FREY, M. R.; MARCUZZO, J. L.; OLIVEIRA, C.. O Balanço Social como Ferramenta de Transparência para o Setor Público Municipal. Revista Universo Contábil, Blumenau, v. 4, n. 2, p. 75-92, 2008. Disponível em:

<http://132.248.9.34/hevila/Universocontabil/2008/vol4/no2/5.pdf >. Acesso em: 01 Novembro 2014.

GERHARDT, T, E; SILVEIRA, D. T. Métodos de pesquisa. Porto Alegre: Editora da UFRGS, 2009.

HISTÓRIA DO GRUPO BARRALCOOL. Disponível em:

<http://barralcool.com.br/?page_id=51>. Acesso em: 13 Outubro de 2014.

IUDÍCIBUS, S.; MARION, J. C. Dicionário de termos de contabilidade. São Paulo: Atlas, 2001.

JANNUZZI, P. M. Indicadores Sociais na Formulação e Avaliação de Políticas Públicas.

Revista de Administração pública. Rio de Janeiro, v. 36, n.1, p. 51-72, 2002. Disponível em: < http://www.enap.gov.br/downloads/ec43ea4findic-curso-texto.pdf >. Acesso em: 25 Março 2015.

KROETZ, C. E. S. Contabilidade social. Revista Brasileira de Contabilidade, Brasília, n.120, p. 21-38, nov./dez. 1999. Disponível em:

<http://www.sebraepb.com.br:8080/bte/download >. Acesso em: 02 Dezembro 2014.

LIMONGI, B. et al. Balanço Social: Convergências e Divergências entre os modelos Ibase, Gri e Instituto Ethos. In: $1^{\circ}$ CONGRESSO UFSC DE CONTROLADORIA E FINANÇAS. Congresso UFSC de Controladoria e Finanças. Florianópolis : UFSC, 2008. Disponível em: <http://dvl.ccn.ufsc.br/congresso/anais/1CCF/20090727145837.pdf >. Acesso em: 15 Março 2015.

NETO, F. P. M; FROES, C. Responsabilidade social e cidadania empresarial: a administração do terceiro setor. Rio de Janeiro: Qualitimark, 1999.

PEREIRA FILHO, J. Metodologia do trabalho científico: da teoria à prática. Tangará da Serra: Gráfica e Editora Sanches Ltda, 2013.

RICO, E. M. A Responsabilidade Social Empresarial e o Estado: uma aliança para o desenvolvimento sustentável. São Paulo em Perspectiva, São Paulo, p. 73-82, 2004. Disponível em: < http://www.scielo.br/scielo.php?script=sci_arttext\&pid=S010288392004000400009>. Acesso em 14 Setembro 2014.

ROVER, A. Metodologia Científica: educação a distância. Joaçaba: Unoesc, 2006. Disponível em: <http://hugoribeiro.com.br/biblioteca-digital/UNOESC-Apost_Metod_Cient1.pdf $>$. Acesso em 06 Novembro 2014. 
SANTOS, L. S. Análise Comparativa dos Indicadores Sociais Internos Das Usinas Barralcool S/A e Itamarati S/A com base na receita Operacional líquida do Período de 2008 e 2010. Trabalho de Conclusão de Curso de Bacharel em Ciências Contábeis, Tangará da Serra: Unemat, 2012.

SILVA, C. A. T.; FREIRE, F. S. Balanço Social: teoria e prática: inclui o novo modelo do IBASE. São Paulo: Atlas, 2001.

SOUZA, C. G.; OLIVEIRA, F. A.; SILVA JUNIOR, L. R. Análise dos Indicadores Sociais Internos de Responsabilidade Social das Médias e Grandes Empresas Certificadas pela Assembléia Legislativa de Mato Grosso. Tangará da Serra: Revista UNEMAT de Contabilidade, p. 188-210, 2013. Disponível em: <http://periodicos.unemat.br/index.php/ruc/article/view/381>. Acesso em: 12 Setembro 2014.

SOUZA, H. Empresa Pública e Cidadã. Disponível em: <http://www.conversascombetinho.org.br/com_a_palavra/balanco.htm> Acesso em: 21 maio 2015.

TAIAROL, S. M.; RAIMUNDINI, S. L.; BEHR, A. Indicadores Sociais Internos e a Geração de Valor Adicionado: uma Análise da Relação do Balanço Social e da Demonstração do Valor Adicionado em Bancos Brasileiros. REUNIR: Revista de Administração, Contabilidade e Sustentabilidade, v. 1, n. 2, p.82-100, Set-Dez/2011. Disponível em: <http://150.165.111.246/revistaadmin/index.php/uacc/article/view/34>. Acesso em: 14 Setembro 2014.

TINOCO, J. E. P. Balanço Social: Uma abordagem da transparência e da responsabilidade pública das organizações. 1. Ed. - 3. reimpr. São Paulo: Atlas, 2006.

TINOCO, J. E. P.; KRAEMER, M. E. P. Contabilidade e gestão ambiental. São Paulo: Atlas, 2006.

TORRES JUNIOR, F.; SILVA, F. R. Balanço social: instrumento de evidenciação dos objetivos sociais. Pensar Contábil, v. 10, n 39, 2008. Disponível em: <http://www.atena.org.br/revista/ojs-2.2.3-08/index.php/pensarcontabil/article/view/109>. Acesso em: 01 Dezembro 2014.

TORRES, C.; MANSUR, C. Balanço social, dez anos: o desafio da transparência. Rio de Janeiro: Ibase, 2008.

TRIVIÑOS, A. N. S. Introdução à pesquisa em ciências sociais: a pesquisa qualitativa em educação. São Paulo: Atlas, 1987.

USINAS ITAMARATI. Perfil histórico da usina, 2014. Disponível em:

<http://www.usinasitamarati.com.br/itamarati/perfil.html>. Acesso em: 13 Outubro de 2014. 